\title{
A CRENÇA EM LOBISOMENS: VISÕES ACERCA DA METAMORFOSE DE HOMENS EM LOBO
}

\section{THE BELIEF IN WEREWOLVES: VIEWS ON THE TRANSFORMATION OF MEN INTO WOLVES}

Resumo: O seguinte artigo busca apresentar, por meio de uma revisão bibliográfica, as principais visões acerca da crença em lobisomens e seus desdobramentos durante os séculos, visto que possuímos fontes sobre a licantropia desde a Antiguidade até a Idade Moderna. Para realização das leituras utilizaremos os conceitos de Roger Chartier, A. J. Gurevich e Stuart Clark. Analisando especificamente o tema da licantropia, apresentarei obras de Carlo Ginzburg, Sabine Baring-Gould, Claude Lecouteux e outros. Estas páginas fazem parte de um projeto de pesquisa em andamento intitulado "Licantropia: uma análise cultural acerca da crença em lobisomens no tratado De la lycanthropie, transformation et extase des sociers (1615), de Jean de Nynauld".

Palavras-chave: Licantropia, Crença, Sabine Baring-Gould, Claude Lecouteux, Carlo Ginzburg, Stuart Clark.

Abstract: This article seeks to present, by means of a bibliographic review, the main views about the belief in werewolves and their developments over the centuries, since we have sources on lycanthropy from Antiquity to the Modern Age. To carry out the readings we will use the concepts of Roger Chartier, A. J. Gurevich and Stuart Clark. Analyzing specifically the theme of lycanthropy, I will present works by Carlo Ginzburg, Sabine Baring-Gould, Claude Lecouteux and others. These pages are part of an ongoing research project entitled "Lycanthropy: a cultural analysis of the

\footnotetext{
${ }^{1}$ Graduanda em História pela Universidade Federal de Santa Maria. Membro do Virtú - Grupo de História Medieval e Renascentista. Bolsista CAPES em Residência Pedagógica. Orientada pelo professor Dr. Francisco de Paula Mendonça Junior. E-mail para contato: gabrielapereira09@outlook.com.
} 
belief in werewolves in the treaty De la lycanthropie, transformation et extase des sociers (1615) by Jean de Nynauld".

Keywords: Lycanthropy, Belief, Sabine Baring-Gould, Claude Lecouteux, Carlo Ginzburg, Stuart Clark.

\section{Introdução}

Ao entrarmos em contato com vestígios anteriores ao século V, notamos que a crença na existência de seres metamorfoseados é amplamente presente. Podendo ser parcial ou total, a transformação em lobo aparece principalmente em fontes folclóricas, como as sagas e contos passados oralmente, e em tratados e manuscritos eclesiásticos. O mito que dá origem à licantropia, segundo Ovídio (2003: 201-206) no livro I da obra Metamorfoses, data da época em que deuses e homens conviviam na terra. Tudo aconteceu quando, após a criação do mundo, chegou aos ouvidos do grande criador os terríveis feitos que Lycaon, rei da Arcádia, estava produzindo. Este sacrificava viajantes que passavam pelo seu território. Sabendo disso, o deus Júpiter resolveu comprovar a veracidade dos fatos, transformando-se em um andarilho e se dirigindo à morada do rei, que o recebeu e o convidou para um jantar em seus aposentos.

Recebendo o viajante e suspeitando dele, o rei decide descobrir na prática se aquele homem era um deus ou um mero mortal, e, para isso, the serve pedaços de carne humana em meio ao jantar. Enfurecido, Júpiter o castiga, transformando-o em fera, mais especificamente em lobo, mantendo sua consciência humana por baixo da cobertura de pelos, mas sendo obrigado a vagar pelo mundo na forma de um animal feroz. 
Esse mito teria dado origem ao que chamamos hoje de licantropia e outros homens transformados em lobo apareceram sucessivamente ao longo dos séculos. Mesmo que a obra date do período antigo, nosso foco principal não é a Antiguidade, mas é de grande valor compreender como esses indivíduos trataram do assunto. Nossa intenção aqui é, a partir de uma breve revisão bibliográfica, lançar um olhar acerca das principais características da crença e de seus desdobramentos ao longo dos séculos, assim como analisar como ela é abordada em estudos recentes. Para tanto, buscamos contextualizar como funcionavam os valores da época, para compreender como eram tratados os acusados de licantropia, como ocorria a transformação, como esses símbolos afetavam direta e concretamente a vida das pessoas e como essas práticas, representações e discursos são tematizados por diferentes autores.

Durante os séculos que compreendem a Idade Média, notamos um esforço da Igreja em pautar os indivíduos e os principais discursos que circulam na sociedade cristã. Sendo assim, podemos analisar diversos discursos produzidos e reproduzidos por eclesiásticos que entram em contato diretamente com a metamorfose em lobo. Apresentaremos em breve um dos mais conhecidos desses, escritor de diversas obras que sobreviveram até hoje, Santo Agostinho.

A visão de que os lobisomens eram apenas fruto da imaginação entra em confronto com diversas formas de se transformar e com uma crença forte no real potencial de transformação humana. Ao longo do artigo, apontaremos esses ritos e como eles eram experienciados pelos sujeitos, 
Cadernos de Clio, Curitiba, v. 11, nº. 2, 2020

lembrando que não nos cabe aqui empregar uma racionalidade e cientificidade atual acima desses relatos. Existem diferentes percepções daquilo que é considerado verdadeiro ou falso, mas é importante que tratemos desse mundo simbólico onde os acontecimentos eram vividos e explicados conforme suas necessidades e compreensões de mundo coletivo sem aplicar pré-conceitos e ceticismos.

Esse tema ainda é pouco trabalhado por pesquisadores, alguns dos quais se dispuseram a falar sobre o assunto consideram o lobisomem uma criação da imaginação dos camponeses que viviam na penúria e que, por isso, imaginavam coisas terríveis. Outros, como apresentarei a seguir, trazem interessantes noções acerca do assunto. Nesse artigo, buscaremos por meio da História Cultural analisar a relevância do lobisomem ao longo dos séculos, a qual desencadeou inúmeros tratados e manuscritos sobre o assunto, assim como gerou enormes tentativas de repressão da Igreja, associando os lobisomens às bruxas e considerando-os heréticos em diferentes períodos.

\section{Trajetória das crenças}

O grande número de fontes que dispomos hoje sobre a metamorfose em lobo se distribui pelo tempo e espaço. Podemos notar a produção de Santo Agostinho, Cidade de Deus, que já no século V buscava explicar a impossibilidade dessas transformações, cunhando o termo phantasticum (LECOUTEUX, 2005: 90), parte mais sensível do corpo durante o sono, que poderia ser manipulado de acordo com as vontades de um demônio, 
que poderia implantar memórias de um lobo atacando pessoas e as matando. Essas ilusões pareciam tão reais que o indivíduo acreditava fielmente na sua transformação e nas atrocidades que teria cometido. Outros muitos clérigos e especialistas negaram a licantropia, podendo-se notar a influência que Agostinho teve sobre muitos sujeitos independente da época. O que nos cabe ressaltar aqui é a importância que a crença teve para os indivíduos e que a sua presença no cotidiano levou à necessidade de produzir-se tratados e manuscritos sobre os assunto.

Esse mundo simbólico referente à crença pode ser notado ao longo dos séculos em diversos âmbitos sociais, ou seja, no modo como os sujeitos se comunicavam, como agiam, como se expressavam pelos mais variados meios — arte, escritos, teatro — , como lidavam com aquilo que lhes era imposto por forças maiores, como produziam discursos e realizavam práticas (PESAVENTO, 2003: 8). A permanência da crença no consciente coletivo de indivíduos de diferentes épocas mostra sua força e relevância para eles.

Nos cabe agora falar um pouco sobre o cotidiano dos sujeitos, como eles agiam no mundo e como suas práticas eram reprimidas ou não pela religião católica. De fato devemos lembrar que antes dessa religião se tornar oficial, muitos elementos pagãos de cultos eram relativizados e viviam lado a lado ao catolicismo. Após a oficialização, houve uma tentativa de suprimir e impor aos fiéis maneiras de agir que seguissem os códigos cristãos. No meio desse processo ocorreram diversas apropriações 
e transformações de aspectos que não foram passíveis de serem apagados e que acabaram, então, sendo adaptados à fé cristã.

\section{A vida cotidiana e as heresias}

Os sonhos, muitas vezes ligados à licantropia, foram vistos de diversas maneiras ao longo do tempo. Com o advento da cristandade, podemos notar um movimento de demonização deles. Até o século III, segundo Le Goff (1994: 147) no livro O Imaginário Medieval, considerava-se que possuíam caráter divino, num momento em que Deus poderia mandar mensagens para os seus fiéis a partir de sonhos que poderiam receber diferentes significados a partir de quem os analisasse. Um dos principais teorizadores da onirologia cristã, estudo dos sonhos, foi Agostinho (LE GOFF, 1994: 315), que apontava que esse suposto contato não passava de imagens produzidas pelas almas, sujeitas e sensíveis a ataques demoníacos, como no caso da licantropia, já citada anteriormente.

A partir do século IV, os eclesiásticos buscam uma forma de mediar esse contato de Deus com os sujeitos, que não era possível se todos pudessem ter sonhos divinatórios. Passa-se então a considerar que eles podem ser dominados por demônios e enviados pelo diabo (LE GOFF, 1994: 311). Essas ilusões produzidas pelo maior inimigo da cristandade levavam o ser humano a cometer heresias permeadas por desejos e pecados. A partir de então, somente alguns santos receberiam visões, normalmente em períodos específicos de suas vidas, como próximo a sua morte (LE GOFF, 1994: 330). 
Esse afastamento dos leigos dos assuntos religiosos é muito aparente, segundo André Vauchez no livro A espiritualidade Medieval (1995: 98). A pregação e a leitura da bíblia estava somente nas mãos dos clérigos e mesmo que a população tentasse, a escrita em latim dificultava mais ainda essa proximidade. Ou seja, a salvação desses indivíduos estava depositada nas mãos daqueles poucos letrados que conduziam as missas e pregavam. Os padres e clérigos eram os mediadores entre Deus e o sujeito comum. Essa mediação em torno de uma ida ao paraíso fazia com que os camponeses comparecessem às obrigações da fé.

Devido ao medo de serem atacados por demônios e bruxas, tentavam se proteger de diversas maneiras, principalmente seguindo ritos cristãos que poderiam manter afastadas as peripécias de Satã. Dentre essas práticas, podemos notar o batismo - as crianças batizadas estariam livres das garras dos lobisomens e das bruxas -, preces, jejuns, bênçãos, objetos sagrados e outros (LE GOFF, 2006: 326). Jean Delumeau (2009: 143), no livro História do Medo no Ocidente, aponta que esses temores amplificavam-se à noite, quando a imaginação dos indivíduos temerosos estava ainda mais acentuada. Porém, nós discordamos dessa visão de que tais representações eram fruto da cabeça de famintos e pobres sujeitos, que devido a tantas dificuldades, agravadas pelo medo, acabavam imaginando feras selvagens. É interessante tentarmos quebrar essa visão de que a Idade Média foi inteiramente permeada por fome, doenças e atrasos. É claro que houve décadas marcadas pela peste, carestia e dificuldades, mas esses momentos também foram seguidos de épocas de boas colheitas, desenvolvimento 
populacional e artístico. Pensar que durante séculos só existiu caos e escuridão é concordar com a noção de "Idade das Trevas", pregada principalmente por iluministas do século XVIII.

Os acusados de licantropia, muitas vezes associados a bruxas, poderiam ser excluídos da sociedade. É importante notar que a exclusão social de um sujeito tem um grande significado, como trata Bronislaw Geremek em um dos capítulos do livro O Homem Medieval (LE GOFF, 1989: 233-234). Além de ser expulso de um grupo social, o indivíduo é também retirado de suas terras, pois não existe a possibilidade de permanecer no local. Sendo assim, aqueles marginalizados poderiam ser ameaçados de morte e até sofrer algum tipo de ataque, tendo que partir para um novo local em busca de se restabelecer e recomeçar.

Mesmo com essa perseguição, práticas antigas e novas permaneciam acontecendo, embora não se encaixassem nos preceitos cristãos. Isso nos mostra que até quando tais crenças eram demonizadas, os sujeitos continuavam acreditando nelas e exercendo-as. Assim, muitos que acreditavam estar acometidos de algum feitiço recorriam, por exemplo, à figura do Diabo para realizar uma troca em prol de ter sua saúde de volta ou ter a proteção de suas terras, animais e família.

Nesse contexto, as lendas sobre lobisomens podem ser encontradas em diversos locais com enormes semelhanças. Dessa forma, as compreendemos como mitos e contos que se difundiram territorial e espacialmente. 


\section{Lobisomens nos mitos}

As características dos lobisomens, presentes nas fontes, variam de acordo com o mito e local em que aparecem referidas. De fato, existem diversas formas de se transformar e, depois, de voltar ao normal. É importante destacar que nesse artigo não vamos discutir acerca da possibilidade de transformação segundo os moldes científicos e racionais na nossa época, assim como buscamos não empregar pré-conceitos atuais que de forma alguma cabem ao tema.

No livro Lobisomem: um tratado sobre casos de licantropia, Sabine Baring-Gould aponta um grande número de casos e de formas de transformação em diferentes regiões. Infelizmente algumas informações não possuem identificação no tempo, porém continuam sendo extremamente importantes para nossa análise, principalmente pela obra ser uma fonte primária. Um dos casos que chama a atenção é o de um menino acusado de matar e alimentar-se de dezenas de crianças na região de Landres, sul da França. O relato do autor também traz todo o processo judiciário do jovem (BARING-GOULD, 2003: 63-70).

Quando tinha dez anos ou onze anos, meu vizinho, Duthillaire, levou-me ao interior da floresta e me apresentou um Sr. de la Forest, um homem negro, que me marcou com a unha e deu a mim e a Duthillaire um unguento e uma pele de lobo. Desde então, vagueio pelo país como um lobo (BARING-GOULD, 2003: 68). 
A transformação a partir de determinados elementos é muito comum, podendo variar entre cintos, anéis, capas, beber água de pegadas, banhar-se em fontes, ser o sétimo filho, unguentos e malefício de bruxas. Um dos casos mais conhecidos, citado por Carlo Ginzburg (2012: 118), é o do lobisomem da Livônia ou lobisomem Thiess, que se transformara pois havia nascido com o pelico. No século XVII, em um processo inquisitorial, descreveu sua ida ao inferno, a qual dizia realizar em torno de quatro vezes por ano para salvar as colheitas que eram roubadas por bruxas. Naquele local, ele e seus companheiros lobisomens lutavam. Caso ganhassem, as colheitas de cereais do período seriam bem sucedidas, mas caso perdessem, sofreriam com meses difíceis para a comunidade. Quando questionado, o homem constantemente aponta que fazia tudo isso em nome de Deus, mesmo que os inquisidores tentassem induzi-lo a confessar uma ligação com a bruxaria.

A volta ao corpo normal após a transformação em lobo variava. No caso da metamorfose por meio de um objeto, o indivíduo voltava a sua forma após tirá-lo do corpo. Em outros casos, era necessário que colocasse as roupas que estava usando antes do processo. Em um caso apontado por Lecouteux (2005: 98), no livro Hadas, Brujas e Hombres lobo en la Edad Media, se o sujeito perdesse suas vestes estaria sentenciado a continuar vagando como um lobo pelo resto de sua vida.

É interessante entendermos como essa crença se tornou tão presente na vida dos indivíduos e de que maneira perpassou longos séculos e esteve presente em tantos locais. Uma maneira de analisar a licantropia é pelo viés 
da linguagem, o qual Stuart Clark aplica sobre a crença em bruxaria no livro Pensando com Demônios. É necessário um olhar sobre os mitos, crônicas, hagiografias, folhetos e outras fontes que podem nos apresentar elementos muito importantes. Dentre eles, citamos os modos pelos quais o lobisomem é representado, tratado pela população e apropriado e modificado pelos diferentes grupos sociais.

\section{Crença e linguagem}

As experiências vividas pelas pessoas são mediadas por diversos símbolos, que empregam significados para todas as interações com o mundo. Estes eram usados pelos sujeitos para explicar a vida em seus mais diversos âmbitos e é importante lembrar que diferentes sociedades têm diferentes meios de se enxergar e de enxergar seu entorno. Sendo assim, diversas comunidades podem ter crenças parecidas, mas cada uma delas terá elementos específicos que as diferenciam. No campo da licantropia, isso pode ser notado, por exemplo, no caso de Thiess, apresentado por Ginzburg (2012: 118), em que, em uma sociedade permeada por cultos agrícolas, o lobisomem desce ao inferno para lutar em prol das colheitas, não atacando sujeitos comuns como na situação tratada acima por Baring-Gould.

Devemos lembrar que essas formas de ver o mundo não devem ser medidas ou comparadas com outras épocas. Considerá-los irracionais ou eventos frutos da imaginação é negligenciar uma cultura que foi muito marcada por uma proximidade entre o humano e o supernatural. Os 
camponeses viviam todos os dias próximos a santos, anjos e demônios e esse contato com o "mágico" foi muitas vezes promovido e encorajado pela religião cristã, que buscava controlá-lo por meio de ritos, relíquias e milagres. Segundo Gurevich (1988: 67) no livro Medieval Popular Culture: Problems of Belief and Perception, para a população não existia uma delimitação efetiva acerca do que era uma "magia boa" e uma "ruim". Ambas produziam objetos protetores - amuletos e relíquias - e eram procuradas pelas pessoas quando sofriam de alguma doença ou malefício.

Nesse contexto, estamos falando de uma maneira de ver o mundo e lidar com ele que vai muito além de uma racionalidade científica atual. $\mathrm{O}$ irreal não nos cabe aqui, até porque as representações formadas sobre a licantropia são cunhadas a partir do real, do vivido e do experienciado. Segundo Stuart Clark (2006: 14), “dizer que uma crença é racional é falar sobre a maneira como ela se sustenta em relação com outras crenças". É pré-conceber que existem certos discursos verdadeiros e outros não, ao passo que a linguagem que foi usada em sua construção e que a representa não é tão importante quanto os valores do que é ou não aceitável. Ainda de acordo com o autor (CLARK, 2006: 27), é através da linguagem que uma crença é ou não autorizada.

Logo, esses indivíduos acreditavam nas transformações da mesma forma que acreditavam no poder das bruxas de causarem doenças, mortes e malefícios. Elementos estes que eram negados e descartados pelos teóricos realistas (CLARK, 2006: 28), os quais consideravam a linguagem como um reflexo e não como um agente e assim acreditavam que as crenças 
deveriam passar por uma verificação empírica, pela qual recebiam denominação de falsas pois não continham referências no mundo real. Como trabalha Gilbert Durand (2004: 9) no livro $O$ imaginário: ensaio acerca das ciências e da filosofia da imagem, esse método de verificação dos enunciados se baseava na lógica binária, ou seja, só existiam duas possibilidades a serem consideradas: o verdadeiro e o falso; e as únicas formas de verificação eram a partir da experiência, as certezas da lógica e a racionalidade.

Nesse caso, podemos supor que uma análise empírica acerca da licantropia a considerasse ilusória/falsa por não inspirar ações significativas no mundo real. Mas quais seriam ações significativas? Contra lobisomens foram movidas caçadas com ou sem recompensas (DELUMEAU, 2009: 104), indivíduos foram expulsos de suas aldeias e pessoas foram julgadas e sentenciadas pelo crime de licantropia. Homens metamorfoseados em lobos foram vistos e sobres eles foram escritos diversos documentos. A transformação era tão temida e causava tanto alvoroço que até na Idade Moderna se viu a necessidade de escrever acerca do assunto, seja para negá-la ou afirmá-la. Sendo assim, concordamos com Clark (2006: 31) na afirmação de que, "para os usuários das crenças, o que é real sobre o mundo é a questão de que tipos de afirmações de parcelas da realidade sua linguagem lhes permite fazer com sucesso". A licantropia era uma realidade e a linguagem a representava. Afirmar a impossibilidade dessa crença por não corresponder aos preceitos lógicos e a testes racionais é uma 
forma errônea de encarar os comportamentos daqueles que partilham de uma mesma ideia. Existem verdades que fogem à lógica.

Em um mundo onde a licantropia era constantemente falada por eclesiásticos e médicos é um tanto equivocado pensar que os indivíduos do período não a vissem como uma realidade. Por meio da linguagem, os clérigos e especialistas produziam seus discursos e eles poderiam chegar de diferentes formas a seus alvos. Mesmo que tentassem desconsiderar a metamorfose em lobo, produzindo suas próprias verdades e buscando que os espectadores vissem o mundo por meio dos seus signos, como muitos fizeram, outros continuavam afirmando sua veracidade (CLARK, 2006: 57). Pode-se pensar que quanto mais se escreveu acerca do assunto, mais ele se tornava presente no cotidiano vivido, ou seja, o que se representava era considerado real (CLARK, 2006: 60).

A possibilidade da transformação de um ser humano em um lobo não era aceita em termos cristãos pois representava que o tão temido inimigo, o oposto de Deus, teria poder suficiente para provocar mudanças físicas na divina criação. Além disso, sendo essa possibilidade não colocada pela divindade, seria como uma forma de segunda criação, dessa vez pelas mãos diabólicas (CLARK, 2006: 256). O único poder pertencente ao Diabo, citado por diferentes autores cristãos, era o de realizar ilusões e peripécias com aqueles que vacilavam na fé. Muitos filósofos naturais também concediam poderes aos demônios, embora outros fenômenos fossem totalmente negados segundo suas categorias de análise (CLARK, 2006: 280). Desse modo, é muito comum que a licantropia seja ligada à bruxaria 
pelos inquisidores e cristãos. Agora, nos cabe analisar como os escritos recentes tratam do tema.

\section{Estudos recentes}

Segundo Carlo Ginzburg (2012: 166), as confissões extraídas pelos inquisidores durante os julgamentos eram muitas vezes manipuladas para que os acusados respondessem alegando sua culpa ou determinada ligação com a bruxaria e com o sabá. É notável que ao longo do livro o autor busque estabelecer a origem da crença em lobisomens, apontando como sendo derivada de um remoto substrato euroasiático (2012: 158). Essa procura pela originalidade não é nossa preocupação. Nós a entendemos como resultante de esquemas mentais e necessidades de cada comunidade que a vive. É incontestável que diferentes locais produzem sua própria visão de um mesmo objeto de acordo com sua realidade.

Outro ponto presente na obra de Ginzburg é o êxtase, normalmente ligado a um substrato xamânico que estaria presente em diferentes crenças. Porém, como cita M. Eliade (2002: 318) no livro O Xamanismo e as Técnicas Arcaicas do Extase, a transformação em lobo não era um aspecto principal para os xamãs, que poderiam se transformar em animais para determinadas funções, embora a licantropia desses indivíduos não seja a mesma de que tratamos. Os xamãs desciam ao inferno para buscar almas perdidas de doentes ou guiar os falecidos e nessa difícil viagem eles poderiam metamorfosear-se em diferentes animais. Contudo, 
diferentemente de muitos relatos de lobisomens que atacavam crianças, mulheres e recém nascidos, usavam a transformação para outros fins.

Ainda no campo do êxtase, Lecouteux (2005: 31) traz a ideia de um outro $\mathrm{Eu}$ - que é também trabalhado por Agostinho ao tecer o termo phantasticum, já mencionado acima -, o chamado Duplo, que deixava o corpo humano durante momentos de catalepsia, letargia ou um sono profundo. Fora do corpo, poderia tomar a forma de diferentes animais, dependendo da função que teria. Normalmente a transformação em lobo estava ligada ao assassinato. Os meios de partir do corpo poderiam se dar de diferentes formas, podendo ser um desejo próprio do indivíduo ou de outra pessoa que estaria precisando de ajuda. Além disso (LECOUTEUX, 2005: 94), a transformação em animal só ocorreria no outro Eu e não no corpo físico, mesmo assim os dois poderiam ser feridos em batalha. Além disso, o Duplo só apareceria quando quisesse, permanecendo invisível aos olhos humanos no resto do tempo.

$\mathrm{O}$ autor também afirma que se deve fazer uma distinção entre as grandes teorias nos tratados especializados $\mathrm{e}$ as crenças populares (LECOUTEUX, 2005: 154). Entretanto, devemos lembrar que essa distinção entre letrados e não letrados traz diversos problemas a nossa pesquisa, visto que trata dos camponeses como não detentores de uma racionalidade que os permita formular informações concretas. Além disso, esquece que muitos letrados poderiam se apropriar de elementos populares e vice-versa. 
Os lobos podem ser ligados às bruxas de diferentes formas. Lecouteux (2005: 70) assinala que muitas vezes esses animais serviam de sela para as feiticeiras, nas quais elas se transportavam para realizar malefícios ou se dirigir ao sabá. Dessa forma, poderiam ser vítimas aleatórias transformadas para determinado fim ou serem servos que elas usavam para realizar seus afazeres. Outra autora que aponta essa ligação é Jane P. Davidson, que na obra Wolves, Witches and Werewolves: Lycanthropy and Wichcraft from 1423 to 1700 busca promover um estudo das imagens de lobisomens presentes em diversos escritos. Segundo a autora:

A trama canina se complica um pouco em um relato de julgamento de cerca de 1450, quando Else von Miersburg, uma bruxa de Lucerne, foi acusada de cavalgar não apenas em um lobo, mas também em um cão encantado. No item 14 das acusações contra ela, descobrimos que em um ato que pode ser melhor descrito como "it couldn't hurt", não apenas Else foi queimada, mas também o foram seu cachorro e seu lobo. É intrigante especular sobre a veracidade dessa história. Else tinha um lobo de estimação? Se levarmos essa história literalmente, ela deveria ter. $\mathrm{O}$ julgamento de Else von Miersburg também fornece um aspecto adicional interessante para muitas das bruxas que montam lobos. Ela era uma notória criadora de mau tempo, especialmente tempestades de granizo (DAVIDSON, 1990: 50, tradução nossa). ${ }^{2}$

\footnotetext{
2 "The canine plot thickens somewhat in a trial account of about 1450 when Else von Miersburg, a witch from Lucerne, was accused of riding about not only on a wolf, but an enchanted dog as well. In Item 14 of the charges brought against her, we discover that in an act which might best be described as "it couldn't hurt", not only Else was burnt, but so also were her dog and her wolf. It is intriguing to speculate about the veracity of this story. Did anyone else have a pet wolf? If we
} 
Após a apresentação de relatos parecidos, Davidson busca dar uma explicação para esses acontecimentos. Estes teriam ocorrido em razão de uma histeria motivada por mudanças climáticas que aconteciam no período estudado e que a população não sabia explicar racionalmente, empregando então as bruxas montadas em lobos. Assim, "a licantropia, como a feitiçaria, era um meio de explicar o comportamento irracional como o assassinato em massa" (DAVIDSON, 1990: 50). Para concluir, a autora aponta que a escassez de imagens deve-se ao fato de a transformação de um homem em lobo ser inacreditável (DAVIDSON, 1990: 60).

Essa ligação entre licantropia e bruxaria foi trabalhada também por Ginzburg (2012: 166), quando aponta que antes de serem considerados seres maléficos, os lobisomens eram considerados vítimas inocentes e até benéficos. Contudo, a partir do século XV, com a busca dos eclesiásticos de construir uma visão negativa do sabá e das bruxas, é a eles atribuídos esse aspecto pejorativo. Além disso, a negação da existência de lobisomens pode ser notada na maioria dos artigos que tratam sobre a temática.

\section{Considerações finais}

A partir da apresentação das obras que tratam da licantropia, consideramos que não nos cabe, como historiadores, tratar dessas fontes com olhos racionalistas e permeados por uma possibilidade ou não

take this story literally, she must have. The trial of Else von Miersburg also provides an interesting additional aspect of many of the wolf-riding witches. She was a notorious maker of bad weather, especially hailstorms" (DAVIDSON, 1990: $50)$. 
científica. Esse tipo de análise não é bem sucedida quando falamos de ambientes permeados por símbolos que vão muito além de um olhar que busca o real ou o irreal. Essa dicotomia não era feita pelos sujeitos. Por isso, entendemos a licantropia como um fenômeno pertencente à realidade dos indivíduos, que a partir dessas vivências moldavam suas vidas e geravam representações, práticas e discursos.

Também não buscamos realizar uma distinção entre uma cultura propriamente popular e uma cultura de elite. Como aponta Chartier (1992: 34-35), os intelectuais incorporam diversos elementos populares e vice-versa. Sendo assim, podemos trabalhar muito melhor usando termos como símbolos e valores que permeiam os sujeitos e que, independente de suas posições, os movem. São como leis universais que moldam os jeitos de viver e se comportar, muitas vezes inconscientes, os quais podemos estudar a partir da História Cultural.

Além disso, o autor (CHARTIER, 1992: 34) aponta que, mesmo quando um determinado grupo social tenta chegar a algum fim por meio de um discurso, a linguagem é permeada por um entendimento próprio, podendo ser percebida e ressignificada por aqueles que a recebem e chegar a práticas adversas. Normalmente esse processo depende daquilo que é interessante para o coletivo. Por essa razão, é possível constatar que as obras sobre a licantropia e as normas impostas pela Igreja que circulam pelo campo social não resultaram no objetivo dos eclesiásticos, pois os indivíduos continuaram acreditando em lobisomens e adotando práticas que lhes eram válidas e necessárias para construir esse mundo simbólico. 
Algumas visões mais recentes consideram a licantropia fruto da mente de camponeses que, por estarem sempre com fome, medo e enfrentando pestes, acabavam imaginando lobisomens (DELUMEAU, 2009: 89). Considerar aqueles sujeitos como irracionais e incapazes de formular críticas e noções de mundo contundentes é um erro que não queremos cometer aqui. Outra visão conhecida é considerar os sujeitos que diziam transformar-se em lobos como doentes mentais. Porém, para aqueles indivíduos isso não estava em pauta. Como aponta Foucault (1978: 12), a imagem do louco surge principalmente no final da Idade Média; logo, os licantropos eram considerados bruxos, heréticos e vítimas mas não loucos pela sua comunidade. A Igreja não os considerava assim, tratando-os muito mais como aqueles que fraquejaram na fé do que como alienados.

Dessa forma, vemos na linguagem um importante meio para o entendimento dessa crença, e é a partir dela que conseguimos afastar as visões racionalistas. É importante que, ao analisarmos os escritos - tanto daqueles eclesiásticos quanto dos filósofos naturais -, consigamos deixar de lado pré-conceitos acerca das formas de comunicação e experiência que eram realizados por esses sujeitos. Tais concepções se diferem da forma que hoje enxergamos o mundo. Diferentes grupos exerciam apropriações e as devolveram para o mundo social por meio da linguagem, da forma que lhes parecia correta. Essas formas de enxergar o mundo e de se enxergar nele não devem ser medidas e classificadas pelo modo empirista de considerar o que é passível de ser verdade ou não. 
Portanto, com base nas considerações feitas ao longo do artigo, entendemos que a licantropia foi apropriada de diferentes formas por diferentes indivíduos. Por essa razão, encontramos fontes que negam as transformações - como o tratado que dá nome a pesquisa, de Jean de Nynauld - e que as afirmam, - como o grande alvo de Nynauld, Jean Bodin, na obra De la Démonomanie des Sorciers (1580) - ao longo dos diversos séculos analisados. Essas fontes buscam, pelos âmbitos religiosos ou científicos, afirmar seus pontos de vista. Mesmo assim, é inegável a experiência dos sujeitos, que desde a Antiguidade conviveram com a licantropia, a definiram e lidaram com ela de acordo com aquilo que thes era cabível.

\section{Referências}

BARING-GOULD, Sabine. Lobisomem: um tratado sobre casos de licantropia. Tradução de Fernanda M. V. de Azevedo Rossi. São Paulo: Madras, 2003.

CHARTIER, Roger. A História Cultural: entre práticas e representações. Tradução de Maria Manuela Galhardo. 2 ed. Lisboa: Difel, 2002.

. El mundo como representación: estudios sobre historia cultural. Barcelona: Editorial Gedisa, 1992.

CLARK, Stuart. Pensando com demônios: A ideia de bruxaria no princípio da Europa Moderna. Tradução de Celso Mauro Paciornik. São Paulo: Editora da Universidade de São Paulo, 2006. 
DAVIDSON, Jane P. Wolves, Witches and Werewolves: Lycanthropy and Witchcraft from 1423 to 1700. Journal of the Fantastic in the Arts, v. 2, n. 4, 1990, p. 47-73.

DELUMEAU, Jean. História do medo no ocidente 1300-1800: uma cidade sitiada. São Paulo: Companhia das Letras, 2009.

DURAND, Gilbert. $O$ imaginário: ensaio acerca das ciências e da filosofia da imagem. Tradução de Renée Eve Levié. $3^{\mathrm{a}}$ ed. Rio de Janeiro: DIFEL, 2004.

ELIADE, Micea. O Xamanismo e as Técnicas Arcaicas do Êxtase. Tradução de Beatriz Perrone-Moisés e Ivone Castilho Benedetti. São Paulo: Martins Fontes, 2002.

FOUCAULT, Michel. História da Loucura. São Paulo: Editora Perspectiva, 1978.

GINZBURG, Carlo. História Noturna. São Paulo: Companhia das Letras, 2012.

GUREVICH, Aron. J. Categories of Medieval Culture. Tradução de G. L. Campbell. Moscou: Routledge \& Kegan Paul, 1985.

. Medieval Popular Culture: Problems of Belief and Perception. Cambridge: Cambridge University Press, 1988.

LECOUTEUX, Claude. Hadas, brujas y hombres lobo en la Edad Média. Edição de José J. de Olañeta. Palma de Mallorca: El Barquero, 2005.

LE GOFF, Jacques. O Imaginário Medieval. Tradução: Manuel Ruas. Lisboa: Editora Estampa, 1994.

OVÍDIO. Metamorfosis. Edição e tradução de Consuelo Alvarez e Rosa Maria Iglesias. 5a ed. Madrid: Cátedra, 2003. 
Cadernos de Clio, Curitiba, v. 11, nº. 2, 2020

VAUCHEZ, André. A espiritualidade na Idade Média ocidental: séculos VIII a XIII. Rio de Janeiro: Jorge Zahar Editor, 1995.

Recebido em: 04/03/2021 Aceito em: 29/03/2021 